\title{
Trans-pacific dust transport: integrated analysis of NASA/CALIPSO and a global aerosol transport model
}

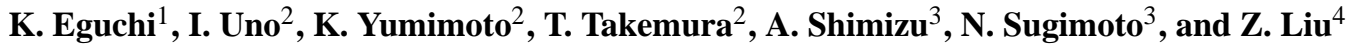 \\ ${ }^{1}$ Department of Earth System Science and Tech., Kyushu University, Fukuoka, Japan \\ ${ }^{2}$ Research Institute for Applied Mechanics, Kyushu University, Fukuoka, Japan \\ ${ }^{3}$ National Institute for Environmental Study, Tsukuba, Ibaraki, Japan \\ ${ }^{4}$ National Institute of Aerospace, Hampton, Virginia, USA
}

Received: 11 August 2008 - Published in Atmos. Chem. Phys. Discuss.: 9 February 2009

Revised: 14 April 2009 - Accepted: 5 May 2009 - Published: 14 May 2009

\begin{abstract}
Detailed 3-D structures of Trans-Pacific Asian dust transport occurring during 5-15 May 2007 were investigated using the NASA/CALIOP vertical-resolved measurements and a three-dimensional aerosol model (SPRINTARS). Both CALIOP and SPRINTARS dust extinctions showed a good agreement along the way of the transport from the dust source regions across North Pacific into North America. A vertically two-layered dust distribution was observed over the northeastern Pacific and North America. The lower dust layer originated from a dust storm generated in the Gobi Desert on 5 May. It was transported at an altitude of around $4 \mathrm{~km}$ MSL and has mixed with Asian anthropogenic air pollutants during the course of transport. The upper dust layer mainly originated from a dust storm that occurred in the Taklimakan Desert 2-3 days after the Gobi dust storm generation. The upper dust cloud was transported in higher altitudes above the major clouds layer during the Trans-Pacific transport. It therefore has remained unmixed with the Asian air pollutants and almost unaffected by wet removal. The decay of its concentration level was small (only one-half after its long-distance transport crossing the Pacific). Our dust budget analysis revealed that the Asian dust flux passing through the longitude plane of $140^{\circ} \mathrm{E}$ was $2.1 \mathrm{Tg}$, and one third of that arrived North America. The cases analyzed in this study revealed that, while the Gobi Desert is an important source that can contribute to the long-range dust transport, the Taklimakan Desert appears to be another important source that can contribute to the dust transport occurring particularly at high altitudes.
\end{abstract}

Correspondence to: K. Eguchi (eguchi@ riam.kyushu-u.ac.jp)

\section{Introduction}

Trans-Pacific transport of mineral dust and air pollutants originating from Asia to North America is well known, based on ground-based and satellite measurements and dust transport model analyses. The average traveling time from Asia to the west coast of North America is approximately 7-10 days. Both mineral dust and air pollutants can be transported simultaneously (e.g. Uematsu et al., 1983; Jaffe et al., 1999; Uno et al., 2001; Takemura et al., 2002a). Results of a multiyear MODIS aerosol optical thickness (AOT) study indicate that $25 \%$ of aerosols that outflowed from the Asian continent reached the west coast of North America and its efficiency is the largest in spring (Yu et al., 2008). The effects of Asian dust on Pacific cloud systems and the associated radiative forcing play a critical role in the climate change. This indirect effect of Asian dust on the climate and its changes has remained unexplored.

Satellite measurements such as the TOMS (OMI) Aerosol Index (AI) and the RGB image sensing provide useful information for elucidating the dust horizontal distribution and day-by-day transport evolution. However, these passive satellite measurements have difficulty in providing dust vertical profiles, information necessary for an accurate evaluation of dust radiative forcing. The Intercontinental Chemical Transport Experiment (INTEX)-B was conducted for a 10week period of 1 March-15 May 2006. The second phase of the INTEX-B campaign specifically examined Asian pollution outflow. McKendry et al. (2008) reported some observational results of Trans-Pacific dust transport together with lidar measurements at Mt. Whistler in British Columbia, Canada. More recently, the PACific Dust EXperiment (PACDEX) 2007 (http://www.eol.ucar.edu/projects/pacdex/)

Published by Copernicus Publications on behalf of the European Geosciences Union. 
was conducted for a pilot study using Lagrangian sampling of aerosol physical and chemical characteristics on board the NSF/NCAR Gulfstream-V research aircraft (G-V). The data was sampled from the lower troposphere to the upper troposphere within dust plumes found over Eurasian, Pacific, and North America. However, the exact transport height and 3D structure of the Asian dust Trans-Pacific transport have not been investigated well.

The space-based two-wavelength, polarization-sensitive backscatter lidar, the Cloud-Aerosol Lidar with Orthogonal Polarization (CALIOP) onboard the Cloud-Aerosol Lidar and Infrared Pathfinder Satellite Observations satellite (CALIPSO) provides continuous global measurements of aerosol and cloud vertical distributions with very high spatial resolution (Winker et al., 2007). Based on CALIPSO observations, Huang et al. (2008) indicated that non-spherical aerosols float up to an altitude of $9 \mathrm{~km}$ around the Asian dust source region, and implied the long-range transport of Asian dust through the upper troposphere. CALIOP is a useful remote sensing tool to provide the detailed dust structure on a global scale. However, the North Pacific Ocean has a high coverage of low clouds during spring seasons. Consequently, CALIOP has difficulty in observing the dust profile beneath thick cloud layers because of the large attenuation of dense clouds to the laser beam. It is usually difficult to capture the daily variation and track the transport of Asian dust using the CALIOP measurement alone.

Very recently, Uno et al. (2008) have demonstrated the capability of an integrated analysis of the CALIOP measurement and a dust transport model to explore the 3-D structure of Asian dust transport from the Chinese desert sources to Japan. In the present study, we have extended this integrated analysis technique to investigation of the structure of dust during the entire course of the Trans-Pacific transport. In this paper, we will present our analysis results and demonstrate an important meteorological phenomenon of the simultaneous transport of Asian dust and anthropogenic pollutants from Asia to North America.

\section{Observation data and model description}

We used the CALIOP Level 1B data products (ver. 2.01), containing the total attenuated backscatter coefficient at $532 / 1064 \mathrm{~m}$ and the volume depolarization ratio at $532 \mathrm{~m}$, in our integrated analysis. In the analysis, the CALIOP data are first averaged to a horizontal resolution of $5 \mathrm{~km}$. We used the depolarization ratio of 0.2 or larger in order to discriminate non-spherical particle from spherical one based on the analysis results of Shimizu et al. (2004). Dust extinction coefficients are then derived from the 5-km lidar data using Fernald's inversion method (Fernald, 1984) by setting the lidar ratio to $\mathrm{S} 1=35 \mathrm{sr}$, as described in detail by Shimizu et al. (2004). The lidar signal inversion is started from an altitude of $14 \mathrm{~km}$ down to the ground surface. The cloud- aerosol discrimination (CAD) score, which is an indicator that enables discrimination between cloud (positive value) and aerosol (negative value) data, is used to help screen out profiles containing cloud signals. We mainly used the nighttime CALIOP measurements and excluded data with low signal-to-noise ratio (SNR). The analytical methods used in this study are identical to those described by Uno et al. (2008) and Yumimoto et al. (2008a).

We used the Spectral Radiation-Transport Model for Aerosol Species (SPRINTARS, Takemura et al., 2000, 2002b, 2005) driven by an atmospheric general circulation model (AGCM, ver. 5.7b), that was jointly developed by the Center for Climate System Research (CCSR)/University of Tokyo, National Institute for Environmental Studies (NIES), and Frontier Research Center for Global Change (FRCGC) (Numaguti et al. 1995). This model simultaneously treats the major tropospheric aerosol components, i.e. carbonaceous (organic and black carbons), sulfate, soil dust, and sea salt. In this study, the horizontal resolution of triangular truncation is set to T106 and vertically 56 layers up to the sigma level of 0.001 (ca. $1 \mathrm{hPa}$ ) are gridded. The emission inventory based on an estimate for year 2000 predicted for the Intergovernmental Panel on Climate Change (IPCC) Special Reports on Emission Scenarios (SRES) A2 scenario is used as input for the anthropogenic air pollutants. Meteorological boundary conditions are taken from the NCEP/NCAR reanalysis data with $2.5^{\circ} \times 2.5^{\circ}$ resolution at 6-h intervals. Model simulation is performed for a time period of 1 January-31 May 2007 with zero initial aerosol concentration. Three-hour averaged model extinction coefficients for each of aerosol species are used in our analyses.

\section{Results and discussion}

\subsection{Transport of Asian dust cloud over North Pacific}

We examined the daily change of the Asian dust cloud transport from the source region to North America occurring during 5-15 May 2007. Figure 1 shows the day-by-day evolution of the dust transport. This figure includes dust aerosol optical thickness (AOT) simulated using SPRINTARS (color), AGCM simulated cloud cover (gray scale), NCEP/NCAR $500 \mathrm{hPa}$ level wind fields (blue vectors) at 00:00 UTC, CALIPSO orbit paths (red and dark blue lines), NOAA/HYSPLIT trajectories (magenta lines; details are described later) along with its positions at 00:00 UTC of each day (marks on the line). Figure $1 \mathrm{a}-\mathrm{f}$ correspond to every other day of 5-15 May. Positions of major high and lowpressure systems on 00:00 UTC of each day are also indicated respectively by characters " $H$ " and " $L$ " in Fig. 1 because dust transport is closely related to these large-scale pressure systems. 

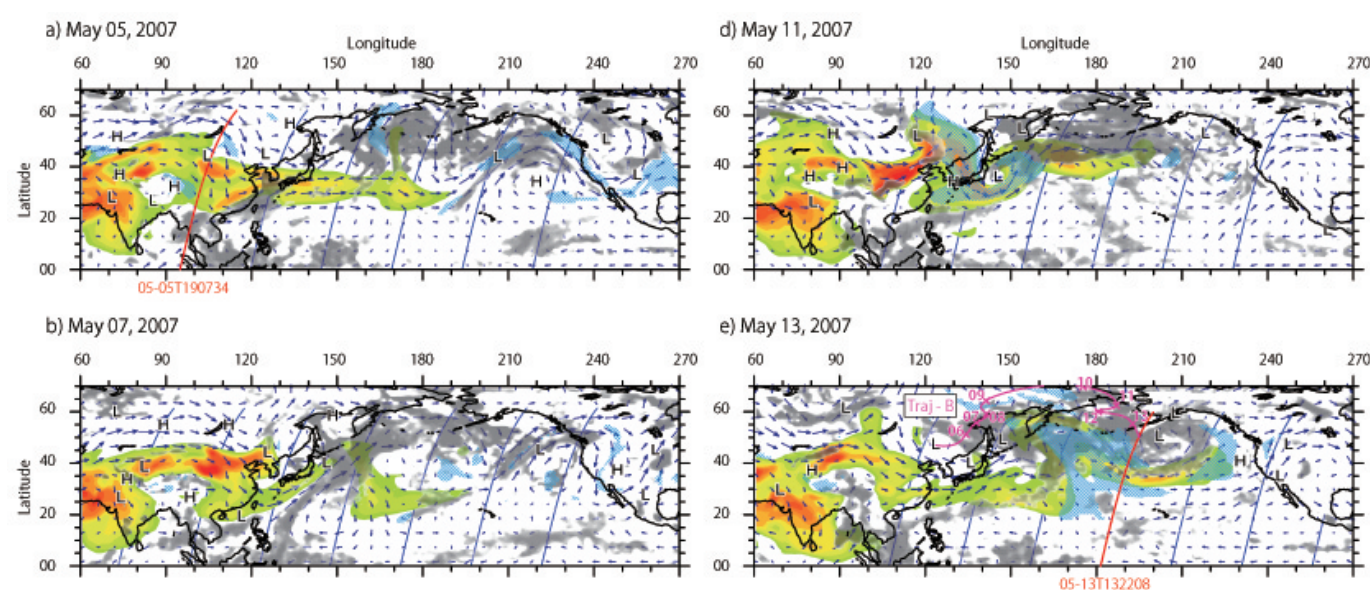

e) May 13, 2007
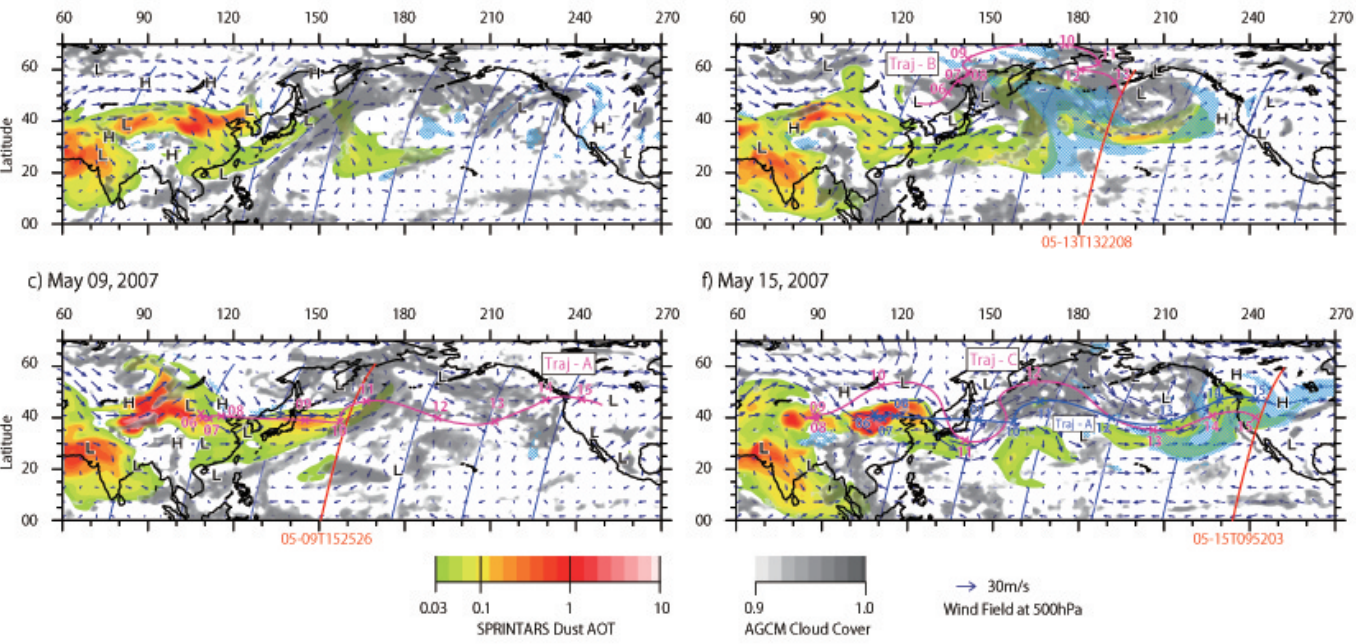

f) May 15,2007

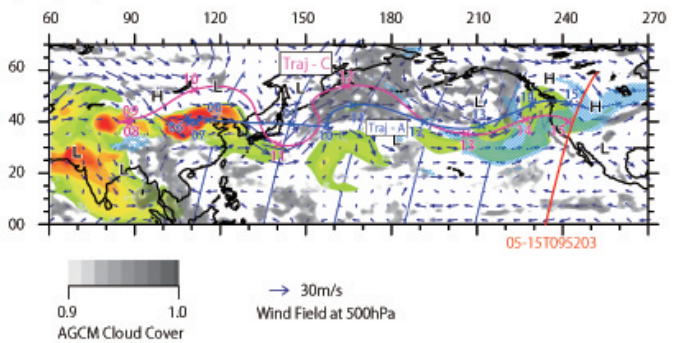

Fig. 1. CALIPSO orbit paths (dark blue and red lines), SPRINTARS dust AOT, AGCM cloud cover and location of major high pressure and low-pressure systems at 00:00 UTC. Vectors indicate the wind field at 500 hPa. Light blue shades represent the region in which the contribution of the upper troposphere (above $8 \mathrm{~km}$ ) to the total dust AOT is greater than $60 \%$. Numbers at the bottom of figure show the CALIPSO path time (MM-DD HHMMSS). The three trajectory lines are described in the text.

As presented in Fig. 1, the CALIPSO satellite passed over the Pacific Ocean approximately five times for the nighttime portion of each day. However, the northern Pacific Ocean, especially the northeastern part, was mostly covered by low clouds during our target period. For this reason, the cloud free CALIOP observations are limited. We selected four CALIPSO orbits to depict the evolution of the dust transport with the help of the aerosol transport model simulation. Figure 2 shows extinction coefficients and depolarization ratios derived from the CALIOP measurements for 5, 9, 13, and 15 May, corresponding to the orbits by the red line in Fig. 1a, c, e, and f. Overlaid on the extinction image plots (left column) are the SPRINTARS simulated dust extinction coefficient (blue solid contours) and potential temperature (black broken lines). The contours of the SPRINTARS dust extinction coefficient are also over plotted on the depolarization ratio images (middle column). The CAD scores from the CALIOP Level 2 products are plotted in the profile plots (right column).

A severe dust storm occurred on 5 May 2007 in southern Mongolia, as shown in Fig. 1a. A high dust AOT area is seen near the China-Mongolia border on 5 May 2007 (Fig. 1a) and it then moves eastward (Fig. 1b). In the extinction image plot of CALIPSO path 05-05T190734 (Fig. 2a), both the
CALIOP observation and the SPRINTARS simulation show a dense dust layer (from the ground to $\sim 2 \mathrm{~km}$ ). The horizontal scale is about $1000 \mathrm{~km}$ derived from the SPRINTARS dust extinction coefficient. Over the dust source region, the CALIOP extinction coefficient is on the order of $0.1 \mathrm{~km}^{-1}$ near the ground surface. The depolarization ratio is large (0.2-0.3). Therefore, this aerosol layer consists mostly of non-spherical particles. This dense dust layer is located at a potential temperature level of $310 \mathrm{~K}$, which is consistent with the previous results obtained by Uno et al. (2008) based on the analysis of the CALIOP measurement and a four-dimensional variational data assimilation version of a regional dust transport model.

After passing over Japan, the dust plume is trapped in a dry slot of a low-pressure system over Kamchatka Peninsula on 9 May (Fig. 1c). Along the CALIPSO orbit path of 0509T152526 (Fig. 2b), a thick aerosol layer is centered around $40^{\circ} \mathrm{N}, 160^{\circ} \mathrm{E}$, extending vertically from $1 \mathrm{~km}$ to $5 \mathrm{~km}$ above mean sea level (MSL) and horizontally $35^{\circ}-43^{\circ} \mathrm{N}$. Judging from the depolarization ratio measurement (middle column in Fig. 2b), this aerosol layer comprises dominantly spherical aerosols for the lower part and dust for the mid-upper part. Judging from CAD value, there are high thick clouds on both sides of the aerosol layer (shaded by light blue on 

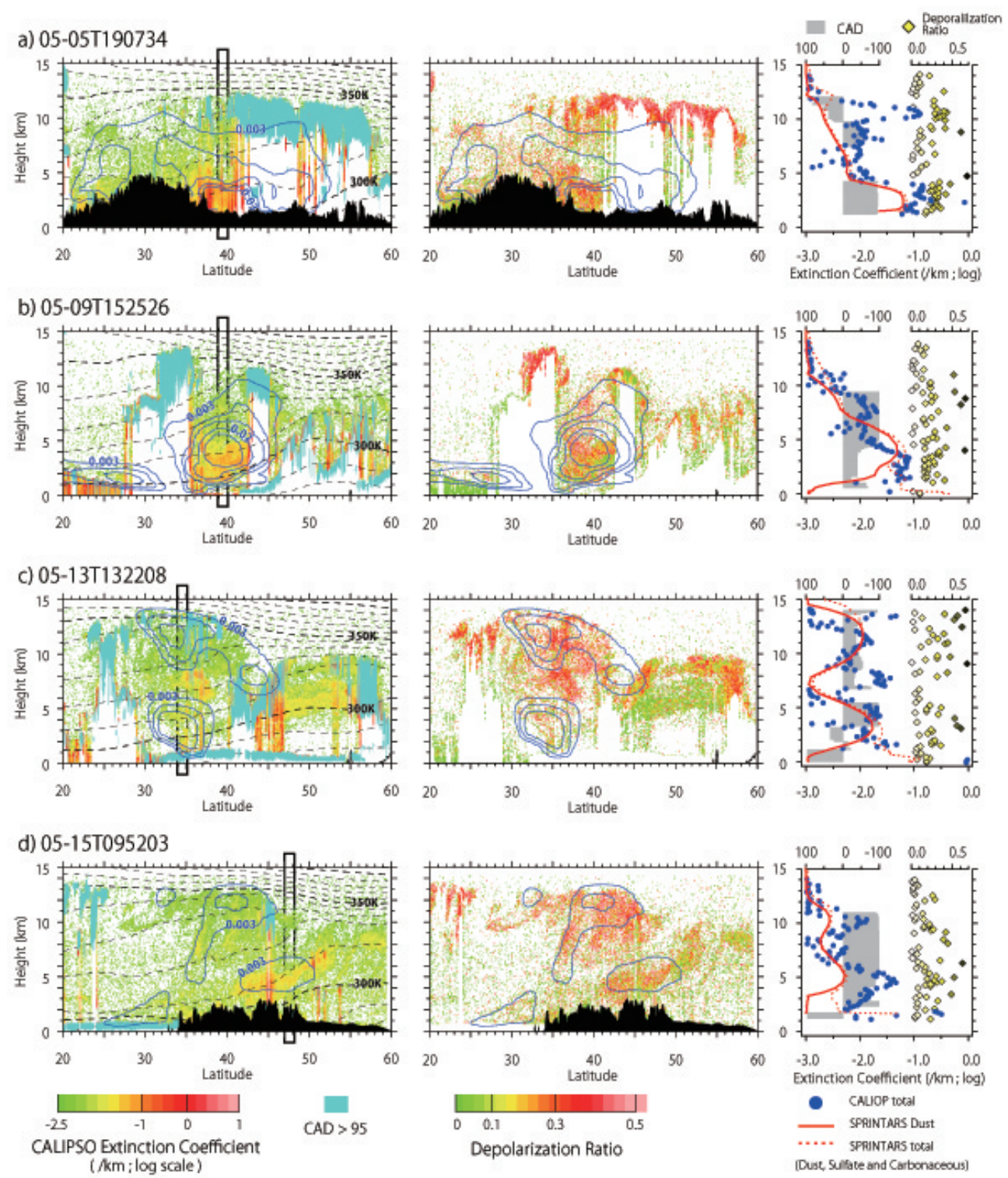

Fig. 2. Vertical cross-section of the CALIPSO observed total extinction coefficients (left column) and particle depolarization ratios at $532 \mathrm{~nm}$ (middle column) for 5 May (a), 9 (b), 13 (c), and 15 (d), overlaid with contours of the SPRINTARS dust extinction coefficient (dark blue lines; interval $0.003,0.006,0.01,0.02,0.03 \mathrm{~km}^{-1}$ ) and potential temperature (dashed black lines). Light blue regions indicate cloud layers indentified by the CALIOP CAD index (CAD >95). Presented in the right column are averaged vertical profiles of the extinction coefficients simulated by SPRINTARS for dust (red solid line) and all aerosol components excluding sea salt (dashed red line), the CALIOP measurements of extinction coefficient (dark blue dots) and particulate depolarization ratio (black symbols). The gray tone regions indicate CAD near the core part of dust clouds. Average region is shown by rectangular box in the left column of figure.

right column of Fig. 2b). The northern one is associated with a low-pressure system located on Kamchatka Peninsula; the southern one is associated with the cold front accompanying this low-pressure system. It is consistent with the modeled cloud distribution (Fig. 1c gray scale) and the location of the low-pressure system (indicated as symbol "L" near $50 \mathrm{~N}$, $160 \mathrm{E}$ on Fig. 1c). The dust plume is transported on the dryslot behind the synoptic cold front. The HYSPLIT trajec- tory analysis is used to examine the origin and fate of this air mass. Both forward and backward trajectories starting from the center of this dust layer are depicted in Fig. 1c by the magenta line (hereinafter, we call these trajectories Traj-A). We discuss more details of this dust along Traj-A in Sect. 3.2.

The dust cloud continues its transport eastward. On 13 May, its front part has passed over the international dateline to near North America (Fig. 1d-e). Two dust layers 
are seen on the 05-13T132208 CALIPSO path shown in Fig. 2c. The SPRINTARS dust extinction coefficient shows two peaks along the path at around $33^{\circ} \mathrm{N}$ and $3 \mathrm{~km}$ MSL and $33^{\circ} \mathrm{N}$ and $12 \mathrm{~km}$ MSL (Fig. 2c). Although the separation between aerosol layers in the CALIOP extinction coefficient is not as clear as simulated by SPRINTARS, the aerosol distributions from SPRINTARS and CALIOP are seen to be fairly consistent. North of $42^{\circ} \mathrm{N}$, a thick aerosol layer exists aloft, which is not seen in the SPRINTARS simulated dust AOT. The depolarization ratio of this layer is small. Therefore, this aerosol layer is inferred to be composed mostly of spherical aerosols (pollution aerosol). The HYSPLIT backward trajectory starting from this spherical aerosol layer $\left(50^{\circ} \mathrm{N}, 195^{\circ} \mathrm{E}\right.$ $5500 \mathrm{~m} \mathrm{MSL}$ at 13:00 UTC on 13 May) is shown also in Fig. 1e indicated by the magenta line (Traj-B). It passes over the Russia-northeast China border on 5 May, where active biomass burning events were revealed by the MODIS RGB images. Therefore, the aerosol layer shown in the northern part of CALIPSO path 05-13T132208 is most likely an origin of the biomass burning activity in Siberia and northeastern China. The CALIOP measured 1064-nm/532-nm attenuated backscatter ratio (though not shown in this paper) for this part of the aerosol layer shows a strong wavelength dependence, which is a typical characteristic of smoke dominant aerosols as observed by CALIOP (Liu et al., 2008), reinforcing the back trajectory analysis.

The dust plume arrived North America on 14-15 May (Fig. 1e-f). Dust was observed by CALIOP over the Rocky Mountains during the CALIPSO path of 05-15T095203 (Fig. 2d). The dust is divided vertically into two layers. The lower layer stretches from $41^{\circ}-53^{\circ} \mathrm{N}$; its southern part almost attaches to the top of the Rocky Mountains, while its northern part is elevated up to about $6 \mathrm{~km}$ MSL. Judging from the relatively low values of the CALIOP observed particle depolarization ratio, the northern part of this lower aerosol layer can be considered as a mixture of dust and pollution. The upper dust layer is located at $32^{\circ}-45^{\circ} \mathrm{N}$ and $6-$ $12 \mathrm{~km}$ MSL. It is optically thinner than the lower layer. This two-layered dust distribution has been simulated correctly by SPRINTARS.

The SPRINTARS simulated and the CALIPSO observed extinction coefficients (right column in Fig. 2) show a good agreement, except for cloud layers (having large positive CAD values), from the dust source region to the northeastern Pacific. However, for the CALIPSO path of 05-15T0952 over North America, SPRINTARS underestimates the extinction coefficient by approximately one order smaller than that observed by CALIOP. The exact reason for this underestimation by SPRINTARS remains unclear.

The HYSPLIT back trajectory starting from the center of the upper dust layer observed by the CALIPSO path of 05-15T095203 is depicted by the magenta line in Fig. If (i.e. Traj-C). This trajectory goes back to the Taklimakan Desert on 8 May. The light blue shade on Fig. 1 represents the region in which the contribution of the upper tro-
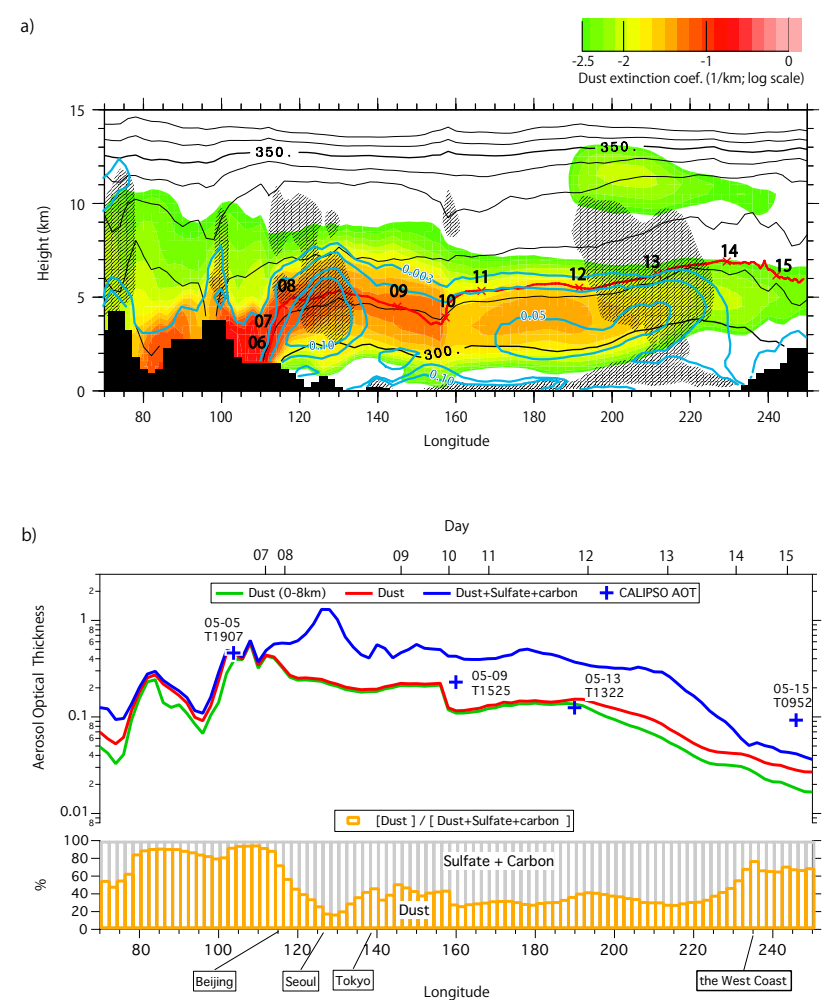

Fig. 3. (a) Vertical longitudinal cross-section of dust extinction coefficient simulated by SPRINTARS for a dust cloud transported in lower altitudes along Traj-A shown in Fig. 1c. The over plotted bold red line is the day-by-day trajectory path height (numbers represent the date of May). Also shown are the SPRINTARS potential temperature (black contour lines) and extinction coefficient of sulfate and carbonaceous contents (light blue contour lines of interval $0.003,0.01,0.05,0.1 \mathrm{~km}^{-1}$ ). The black shaded regions represent the AGCM simulated clouds (cloud water/ice mass content $>10^{-6} \mathrm{~kg} / \mathrm{m}^{3}$ ). (b) Variations of aerosol optical thicknesses simulated by the SPRINTARS along the Traj-A. The red line is total dust AOT; the green line is the dust AOT between the surface and $8 \mathrm{~km}$ height. The blue line is the total AOT for dust, sulfate, and carbonaceous aerosols. The fraction of dust AOT to total AOT is shown on the bottom.

posphere ( $>8 \mathrm{~km}$ ) to the total dust AOT is greater than $60 \%$. On 11 May, the light blue shaded region appears over Japan; it moves eastward further along Traj-C, and finally catches up the dust plume generated in the Gobi Desert on 5 May (i.e. Traj-A). It is interesting that the two large dust clouds emitted from two different sources (i.e. the Gobi and Taklimakan Deserts) were transported simultaneously from the Northeastern Pacific to North America. More detailed analyses will be presented in Sect. 3.2.

\subsection{Lagrangian analysis of dust cloud}

Figure 3 shows a vertical cross-section of the SPRINTARS simulated dust extinction coefficient for the lower level dust 


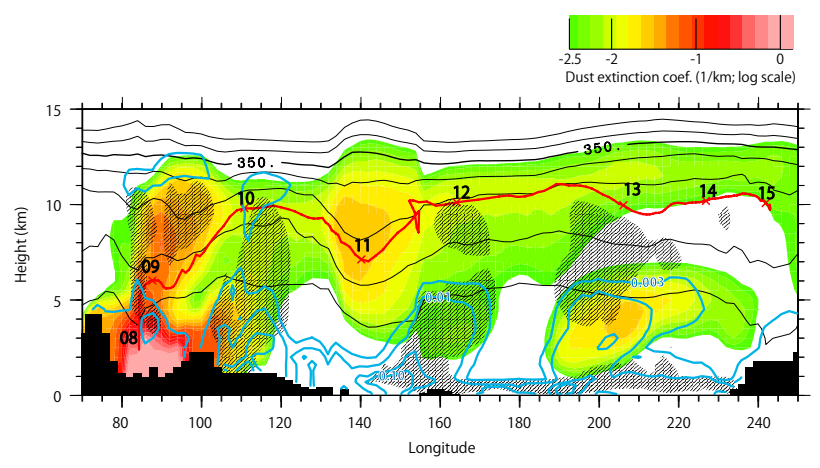

Fig. 4. As in Fig. 3a, except for Traj-C.

cloud along Traj-A, day-by-day trajectory (red bold line), and potential temperature (black line). The light blue contours depict the extinction coefficient of sulfate and carbonaceous contents from SPRINTARS; the black shaded regions portray the AGCM simulated clouds (cloud water/ice mass content $>10^{-6} \mathrm{~kg} / \mathrm{m}^{3}$ ).

Lower panel of Fig. 3 presents variations of the aerosol optical thicknesses simulated by SPRINTARS along Traj-A. The red line is the dust AOT for the whole column of the atmosphere, the green line is the dust AOT below $8 \mathrm{~km}$, and the blue line represents the total AOT including dust, sulfate and carbonaceous aerosols. The AOT integrated from the averaged CALIOP total extinction coefficient (right column in Fig. 2) is also indicated by blue symbols in Fig. 3b. The fraction of the dust AOT to the total AOT is shown in the bottom panel.

Based on the SPRINTARS simulation, the lower level dust clouds are transported between the potential temperatures of $300 \mathrm{~K}$ and $310 \mathrm{~K}$ and the center of the transport height is at approximately $4 \mathrm{~km}$. Over the North Pacific Ocean east of $150^{\circ} \mathrm{E}$, a thick low cloud exists from the sea surface to $1-2 \mathrm{~km}$ height. The dust cloud is transported above this low cloud, which is consistent with the CALIOP observation (Fig. 2).

The maximum dust AOT is located over the desert source region near $110^{\circ} \mathrm{E}$. The maximum total AOT is located near $130^{\circ} \mathrm{E}$ after the injection of large amounts of anthropogenic pollutants in China. The dust AOT level decreases to onetenth of the peak value after crossing the Pacific (estimated from the decay of the peak value from the SPRINTARS dust extinction coefficient between $140^{\circ} \mathrm{E}$ and $230^{\circ} \mathrm{E}$ ). This dust AOT decay is consistent with the values calculated by Takemura et al. (2002a), who estimated that $10-20 \%$ of dust AOT over Japan reaches North America. In the present study, the contribution of dust AOT to total AOT is approximately $30 \%$ between $120-220^{\circ} \mathrm{E}$. It then increases to $70 \%$ at $230^{\circ} \mathrm{E}$. Possible reasons for the increase in the dust contribution over the Northeastern Pacific can be the following. As indicated in the Fig. 3a, the main transport height of air pollutants (about
$2 \mathrm{~km}$ ) is less than that of dust (about $4 \mathrm{~km}$ ) over the Eastern Pacific. Wind fields of these heights differ from each other. The height of Trajectory-A corresponds approximately to main transport height of dust. So the air pollutants goes different path from Traj-A. The increase in the dust AOT likely indicates a decrease in the pollutant AOT along the dust transport path.

Contributions of dust from the lower troposphere below $8 \mathrm{~km}$ to the total column dust AOT decrease east of $190^{\circ} \mathrm{E}$. This is because the upper dust cloud generated few days later in the Taklimakan Desert is transported faster and catches up the lower dust cloud, as mentioned earlier in Sect. 3.1.

Figure 4 presents the SPRINTARS dust extinction coefficient and potential temperature along the trajectory Traj-C (same as in Fig. 3a). A low-pressure system passed from the Taklimakan Desert to the Gobi Desert during 8-10 May and produced a severe dust storm in the Taklimakan Desert. In the Tarim Basin, springtime dust storms are mainly generated by a mesoscale cold wind system induced by a synoptic-scale cold air mass behind a cold front. Aoki et al. (2005) classified the course of introduction of the mesoscale cold wind into the basin into three patterns. The dust event that occurred during 8-10 May 2007 belongs to their first pattern. This pattern is characterized by the easterly mesoscale cold wind, which separates from the synoptic-scale cold westerly and turns its direction westward after going around the eastern side of the Tian Shan Mountains. A large dust storm occurs within the Tarim Basin before the main cold front descends to the basin. Dust particles are then highly lifted up by strong wind and then injected into the warm sector of the low-pressure system, which can carry dust particles to the upper troposphere. This can be one mechanism for the formation of the highly elevated Taklimakan dust layer as observed by CALIOP.

This highly elevated Taklimakan dust plume outflows eastward. Over the Pacific Ocean, the core of this dust layer is at a potential temperature of approximately $330 \mathrm{~K}$ and gradually ascends from $9 \mathrm{~km}$ at $140^{\circ} \mathrm{E}$ to $12 \mathrm{~km}$ at $240^{\circ} \mathrm{E}$ as it moves eastward. The top of the dust layer almost reaches the tropopause. It is important to note that, because this upper level dust is transported in the high troposphere over the polluted eastern coastal region of Asia, this dust cloud is considered to have remained unpolluted during the transport over the land and the Pacific. This is verified by the high values of depolarization ratio measured by CALIOP for this upper dust cloud. Because it is transported at high altitudes above most clouds, this dust cloud is also considered to have remained almost unaffected by the wet removal process. In addition, the vertical gradient of potential temperature around the transport height is large (about $10 \mathrm{~K} / \mathrm{km}$ ) so that the dust is well confined vertically at a nearly unchanged high level. Yumimoto et al. (2008b) presented another similar case of Taklimakan dust transport in the high troposphere. Aoki et al. (2005) analyzed major dust storms on the Tarim Basin over the period of March to May from 1998 to 2001 and assigned six in the thirty events to the pattern of the same as 


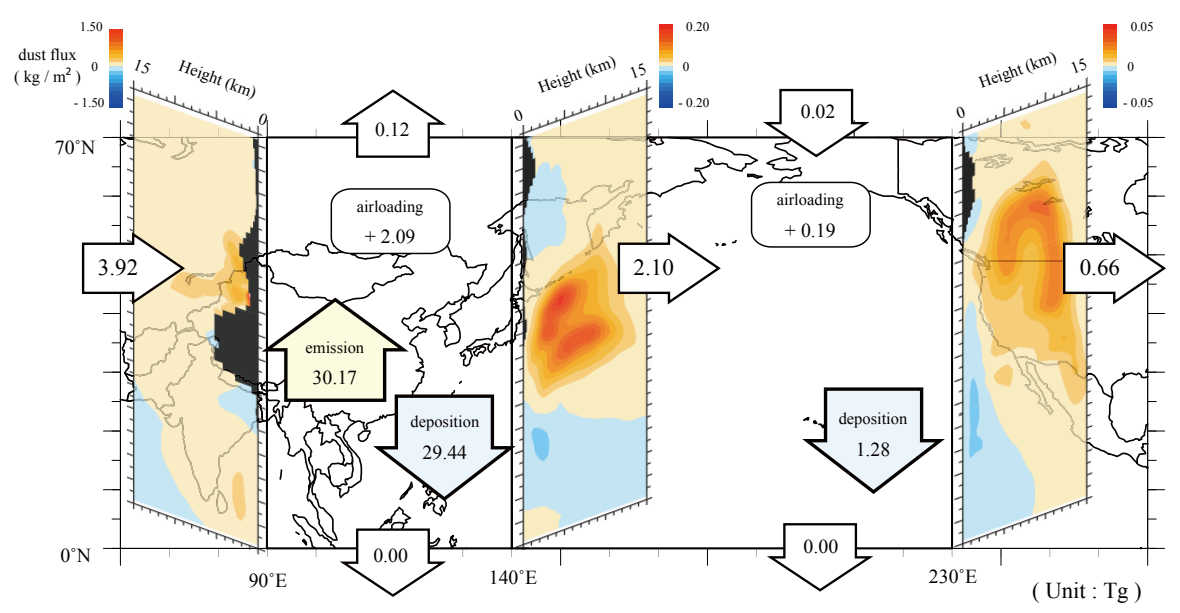

Fig. 5. Horizontal dust transport flux and dust budget simulated by SPRINTARS for a time period of 5-15 May 2007.

our current study. So that Taklimakan dust events similar to which indicated in our study seem to occur several times during the springtime.

As for the variation of dust transport height, recently Generoso et al. (2008) indicated that the top altitudes of the Saharan dust layers over the Atlantic vary seasonally from $4 \mathrm{~km}$ in winter to $8 \mathrm{~km}$ in summer. Meanwhile our study shows that Asian dust layers have multi transport heights from $4 \mathrm{~km}$ to $10 \mathrm{~km}$ during the springtime and those heights depend on the topography of the dust source regions. Table 1 presents a summary of dust cloud characteristics along Traj-A and TrajC.

\subsubsection{Dust transport flux and budget analysis}

Uematsu et al. (2003) reported that the outflow of mineral dust particles generated in the Asian continent and transported from $120^{\circ} \mathrm{E}$ to $165^{\circ} \mathrm{E}$ occurs mainly at $25^{\circ} \mathrm{N}-55^{\circ} \mathrm{N}$. Dust inflow to this domain is $320 \mathrm{Tg} / \mathrm{yr}$. Approximately $60 \%$ of this amount is transported further eastward, crossing longitude $165^{\circ} \mathrm{E}$ in the free troposphere. Similarly, Yu et al. (2008) estimated that about $18 \mathrm{Tg} / \mathrm{yr}$ pollution aerosol is exported from eastern Asia to the northwestern Pacific Ocean, of which about $25 \%$ reaches the west coast of North America, based on the MODIS observations of fine-mode and coarse-mode aerosol optical thicknesses. Although our current study is focused on a short time period of approximately 10 days in May and the meteorological conditions are different from the mentioned other studies, it is useful to examine the dust budgets for this time period considered in our analysis for a comparison with the pervious studies.

Figure 5 shows vertical latitudinal distributions of horizontal dust transport flux at longitudes of $90^{\circ} \mathrm{E}, 140^{\circ} \mathrm{E}$ and $230^{\circ} \mathrm{E}$ and dust budget simulated by the SPRINTARS for a time period of 5-15 May, 2007. In this budget analysis, the northern boundary is set at $70^{\circ} \mathrm{N}$; the southern boundary is set at $0^{\circ} \mathrm{N}$. During the simulated 11-day period, the total amount of dust emitted between $90^{\circ} \mathrm{E}-140^{\circ} \mathrm{E}$ (mainly from the Gobi Desert) and dust transported through the longitudinal cross-plane at $90^{\circ} \mathrm{E}$ (mainly emitted from the Taklimakan Desert) is approximately $34.1 \mathrm{Tg}$. Most of this amount of dust $(29.4 \mathrm{Tg}$ ) deposits onto the ground of the region between $90-140^{\circ} \mathrm{E}$. The dust mass horizontally passing through the longitudinal plane at $140^{\circ} \mathrm{E}$, mainly occurring at latitudes of $25^{\circ} \mathrm{N}-55^{\circ} \mathrm{N}$, is $2.1 \mathrm{Tg}$. Our study also revealed that $0.66 \mathrm{Tg}, \sim 30 \%$ of the exported dust at $140^{\circ} \mathrm{E}$, is transported eastward across $230^{\circ} \mathrm{E}$ and arrives in North America. Because of the two-layered dust structure at the west coast of North America, the transported dust mass flux also shows a two-layer structure. About $60 \%$ of the dust mass flux (approximately $0.4 \mathrm{Tg}$ ) is transported at high altitudes above $8 \mathrm{~km}$. Our estimation of the exported mass flux ratio is quite consistent with that reported by Yu et al. (2008).

With the information of dust vertical distribution provided by the CALIOP measurements, together with the dust transport model, our study has verified that, while the Gobi Desert mainly contribute to the dust cloud transported in the lower troposphere, the Taklimakan Desert contributed to the dust cloud transported in the higher troposphere. A previous study by Liu et al. (2008) based on the first year of the CALIOP measurement revealed that the Taklimakan Desert is a more persistent and prolific dust source compared with the Gobi Desert. The present study implies that the Taklimakan Desert may also play an important role in the long-range dust transport particularly occurring at high altitudes.

\section{Conclusions}

We presented a 3-D analysis of Asian dust transport processes over the Northern Pacific Ocean occurring during 5-15 May 2007, based on the vertical-resolved dust 
Table 1. Summary of dust clouds for two different transport passes.

\begin{tabular}{|c|c|c|}
\hline Dust origin and period & $\begin{array}{l}\text { Trajectory A } \\
5 \text { May from Gobi Region }\end{array}$ & $\begin{array}{l}\text { Trajectory C } \\
\text { 8-9 May from Taklimakan Region }\end{array}$ \\
\hline \multirow{2}{*}{$\begin{array}{l}\text { Main transport height and transport } \\
\text { mechanism }\end{array}$} & $4-6 \mathrm{~km}$ & $8-11 \mathrm{~km}$ \\
\hline & Dry Slot of Cold Front & $\begin{array}{l}\text { Highly lifted up by strong wind and elevated by } \\
\text { updraft accompanied with mesoscale warm sector } \\
\text { and then transported by prevailing westerlies }\end{array}$ \\
\hline Potential temperature level & $300-320 \mathrm{~K}$ & $320-350 \mathrm{~K}$ \\
\hline Horizontal transport speed & $1400 \mathrm{~km} / \mathrm{day}$ & $2000 \mathrm{~km} /$ day \\
\hline Horizontal dust scale ${ }^{\mathrm{a}}$ & $1000 \mathrm{~km}$ & $1500 \mathrm{~km}$ \\
\hline Mixing with anthropogenic Pollutants & Yes & No \\
\hline Typical decay ratio of dust extinction & 0.1 & 0.5 \\
\hline coefficient during Trans-Pacific Transport & $\left(0.1 \rightarrow 0.01 \mathrm{~km}^{-1}\right)^{\mathrm{b}}$ & $\left(0.01 \rightarrow 0.005 \mathrm{~km}^{-1}\right)^{\mathrm{b}}$ \\
\hline
\end{tabular}

${ }^{a}$ Horizontal dust scale was determined from the contour level of $3 \times 10^{-3} \mathrm{~km}^{-1}$ of dust extinction level by the SPRINTARS (this is an e-folding level of dust level by SPRINATS over the Pacific Ocean).

${ }^{\mathrm{b}}$ Estimated from the decay of the peak value from the SPRINTARS dust extinction coefficient between $140^{\circ} \mathrm{E}$ and $230^{\circ} \mathrm{E}$.

measurements provided by the NASA/CALIOP onboard the CALIPSO satellite, together with the global aerosol climate model, SPRINTARS. The analysis results showed a good agreement between the CALIOP observed and SPRINTARS simulated large-scale dust transport processes and structures, which validated the CALIOP measurement and the SPRINTARS simulation each other. The analysis demonstrated the complicity of dust transport processes and multi-layered structure.

Two different Asian dust storms occurred, respectively, in the Gobi Desert on 5 May 2007 and in the Taklimakan Desert few days later. In the following days two dust clouds emitted from these two dust storms were transported across the North Pacific. Over the eastern North Pacific the dust cloud originating in the Taklimakan Desert caught up the dust cloud generated few days earlier in the Gobi Desert and both were transported simultaneously into North America. A twolayered dust structure therefore formed and was observed over the Rocky Mountains. The dust cloud mainly originating from the Gobi Desert was transported at lower altitudes of 4-6 km MSL crossing the Pacific to North America. The transport took about 10 days and has remained trapped within the potential temperature zone of 300-310 K. This dust cloud has also mixed with Asian anthropogenic air pollutants during its travel over land. The AOT ratio of dust to the total (including dust, sulfate, and carbonaceous) was about 0.3 over the North Pacific and increased when arriving the coastal region of North America. The AOT level of this lower dust layer decayed to one-tenth of the peak value when arriving North America.

The dust cloud transported in higher altitudes originated in the Taklimakan Desert where dust particles were lifted up by a low-pressure system to the high troposphere reaching the tropopause level. The height of the core part of this dust cloud is at the potential temperature of $330 \mathrm{~K}$, corresponding to an altitude of about $10 \mathrm{~km}$ (MSL) during its Trans-Pacific transport. Because of the high altitude of the transport, this dust cloud has remained uncontaminated with Asian air pollutants and almost unaffected by wet removal. The decay of its concentration level is relatively small (only one-half during its long-distance transport across the Pacific).

Our dust budget analysis showed that Asian dust flux passing through the longitude plane of $140^{\circ} \mathrm{E}$ was $2.1 \mathrm{Tg}$, of which one-third crossed over $230^{\circ} \mathrm{E}$ and arrived at North America during the time period of 5-15 May 2007 simulated in our analysis.

Extinction coefficients by SPRINTARS are underestimated during the long-range transport compared with CALIOP observations. There seems to be relatively large uncertainties on a dust emission from the Tarim Basin and dust deposition processes. There is room for improvement on these points.

With the vertical-resolved dust measurements provided by CALIOP, together with 3-D dust transport model simulations, our study has implied that, the Taklimakan Desert is not only a persistent and prolific dust source but also a source that can contribute to the long-range dust transport to North America.

Acknowledgements. This study was supported in part by the Global Environment Research Fund, Ministry of Environment, Japan (C-061) and by funds from the Grant-in-Aid for Scientific Research in Priority Areas "Western Pacific Air-Sea Interaction Study (W-PASS)" under Grant No. 18067005 from Ministry of Education, Culture, Sports, Science and Technology (MEXT), Japan. This research is a contribution of IGBP/SOLAS activity. The CALIPSO data were obtained from the NASA Langley Research Center Atmospheric Sciences Data Center.

Edited by: K. Lehtinen 


\section{References}

Aoki, I., Kurosaki, Y., Osada, R., Sato, T., and Kimura, F.: Dust storms generated by mesoscale cold fronts in the Tarim Basin, Northwest China, Geophys. Res. Lett., 32, L06807, doi:10.1029/2004GL021776, 2005.

Fernald, F. G.: Analysis of atmospheric LIDAR observation: Some comments, Appl. Opt., 23, 652-653,1984.

Generoso, S., Bey, I., Labonne, M., and Bre'on, F.-M.: Aerosol vertical distribution in dust outflow over the Atlantic: Comparisons between GEOS-Chem and Cloud-Aerosol Lidar and Infrared Pathfinder Satellite Observation (CALIPSO), J. Geophys. Res., 113, D24209, doi:10.1029/2008JD010154, 2008.

Hara, Y., Yumimoto, K., Uno, I., Shimizu, A., Sugimoto, N., Liu, Z., and Winker, D. M.: Asian dust outflow in the PBL and free atmosphere retrieved by NASA CALIPSO and an assimilated dust transport model, Atmos. Chem. Phys., 9, 1227-1239, 2009, http://www.atmos-chem-phys.net/9/1227/2009/.f0

Huang, J. P., Minnis, B., Chen, Z., Huang, Z., Liu, Q., Zhao, Y., Yi, and Ayers, J. K.: Long-range transport and vertical structure of Asian dust from CALIPSO and surface measurements during PACDEX, J. Geophys. Res., 113, D23212, doi:10.1029/2008JD010620, 2008.

Jaffe, D., Anderson, T., Covert, D., Kotchenruther, R., Trost, B., Danielson, J., Simpson, W., Berntsen, T., Karlsdottir, S., Blake, D., Harris, J., Carmichael, G., and Uno, I.: Transport of Asian Air Pollution to North America, Geophys. Res. Lett. 26, 711714, 1999.

Liu, Z., Liu, D., Huang, J., Vaughan, M., Uno, I., Sugimoto, N., Kittaka, C., Trepte, C., Wang, Z., Hostetler, C., and Winker, D.: Airborne dust distributions over the Tibetan Plateau and surrounding areas derived from the first year of CALIPSO lidar observations, Atmos. Chem. Phys., 8, 5045-5060, 2008, http://www.atmos-chem-phys.net/8/5045/2008/.

McKendry, I. G., Macdonald, A. M., Leaitch, W. R., van Donkelaar, A., Zhang, Q., Duck, T., and Martin, R. V.: Trans-Pacific dust events observed at Whistler, British Columbia during INTEX-B, Atmos. Chem. Phys., 8, 6297-6307, 2008, http://www.atmos-chem-phys.net/8/6297/2008/.

Numaguti, A., Takahashi, M., Nakajima, T., and Sumi, A.: Development of an atmospheric general circulation model, in Climate System Dynamics and Modeling, edited by Matsuno, T., 1-27, Cent. for Clim. Syst. Res., Univ. of Tokyo, Tokyo, 1995.

Shimizu, A., Sugimoto, N. I., and Matsui et al.): Continuous observations of Asian dust and other aerosols by polarization lidars in China and Japan during ACE-Asia, J. Geophys. Res., 109, D19S17, doi:10.1029/2002JD003253, 2004.
Takemura, T., Okamoto, H., Maruyama, Y., Numaguti, A., Higurashi, A., and Nakajima, T.: Global three-dimensional simulation of aerosol optical thickness distribution of various origins, J. Geophys. Res., 105, 17853-17873, 2000.

Takemura, T., Uno, I., Nakajima, T., Higurashi, A., and Sano, I.: Modeling study of long-range transport of Asian dust and anthropogenic aerosols from East Asia, Geophys. Res. Lett., 29(24), 2158, doi:10.1029/2002GL016251, 2002a.

Takemura, T., Nakajima, T., Dubovik,O., Holben, B. N., and Kinne, S.: Single scattering albedo and radiative forcing of various aerosol species with a global three-dimensional model, J. Climate, 15, 333-352, 2002b.

Takemura, T., Nozawa, T., Emori, S., Nakajima, T. Y., and Nakajima, T.: Simulation of climate response to aerosol direct and indirect effects with aerosol transport-radiation model, J. Geophys. Res., 110, D02202, doi:10.1029/2004JD005029, 2005.

Uematsu, M., Wang, Z., and Uno, I.: Atmospheric input of mineral dust to the western North Pacific region based on direct measurements and a regional chemical transport model, Geophys. Res. Lett., 30(6), 1342, doi:10.1029/2002GL016645, 2003.

Uno, I., Amano, H., Emori, S., Kinoshita, K., Matsui, I., and Sugimoto, N.: Trans-Pacific yellow sand transport observed in April 1998: A numerical simulation, J. Geophys. Res., 106(D16), 18331-18344, 2001.

Uno, I., Yumimoto, K., Shimizu, A., Hara, Y., Sugimoto, N., Wang, Z., Liu, Z., and Winker, D. M.: 3-D Structure of Asian Dust Transport revealed by CALIPSO Lidar and a 4DVAR Dust Model, Geophys. Res. Lett., 35, L06803, doi:10.1029/2007GL032329, 2008.

Yumimoto, K., Uno, I., Sugimoto, N., Shimizu, A., Liu, Z., and Winker, D. M.: Adjoint inversion modeling of Asian dust emission using lidar observations, Atmos. Chem. Phys., 8, 28692884, 2008A.

Yumimoto, K., Uno, I., Tanaka, M., Hara, Y., Shimizu, A., and Sugimoto, N.: Elevated Large-Scale Dust Veil Originated from the Taklimakan Desert, 24th International Laser Radar Conference, Boulder, US, June 2008b.

Yu, H., Remer, L. A., Chin, M., Bian, H., Kleidman, R. G., and Diehl T.: A satellite-based assessment of transpacific transport of pollution aerosol, J. Geophys. Res., 113, D14S12, doi:10.1029/2007JD009349, 2008.

Winker, D. M., Hunt, W. H., and McGill, M. J.: Initial performance assessment of CALIOP, Geophys. Res. Lett., 34, L19803, doi:10.1029/2007GL030135, 2007. 